\title{
De la reivindicación política a la industrial: la cultura en la Transición a través de tres documentales musicales
}

From Political to Industrial Vindication: Culture during the Spanish Transition through the Analysis of Three Music Documentaries

Laura Gómez Vaquero

UNIVERSIDAD CAMILO JosÉ CELA· laura.g.vaquero@gmail.com

Profesora en el Grado de cine de la Universidad Camilo José Cela y Doctora en Historia del cine. Ha publicado Las voces del cambio. La palabra en el documental durante la transición en España (2012) y coeditado los libros Piedra, papel y tijera: collage y cine documental (2009) y El espíritu del caos. Representación y recepción de las imágenes durante el franquismo (2009). Ha participado en congresos nacionales e internacionales y escrito más de 40 textos para revistas, catálogos y libros colectivos. Es Jefa de Redacción de Secuencias. Revista de Historia del Cine. Sus áreas de investigación son el cine documental, las relaciones entre cine y mujer y el cine español de los años 60 y 70, con especial atención a la consideración de las prácticas cinematográficas en el marco de la producción cultural del momento.

RECIBIDO: 10 DE NOVIEMBRE DE 2014

ACEPTADO: 14 DE DICIEMBRE DE 2014

Resumen: La Movida ha quedado en el imaginario colectivo como la manifestación más evidente de la consecución de la libertad de expresión, por la que se apostó durante los años de transición de la dictadura a la democracia. Sin embargo, antes de la explosión de este fenómeno cultural, otros habían sido calibrados en términos similares. El acercamiento a los documentales musicales La nova cançó (1976), Canet Rock (1976) y Nos va la marcha (1979) nos permitirá comprobar cómo, durante la segunda mitad de los años setenta, estos fenómenos musicales surgidos en los márgenes eran considerados lugares donde ejercer la democracia de manera efectiva; podremos también observar cómo, con la progresiva incorporación del país a las cada vez más estrictas dinámicas de la sociedad de consumo, el elemento aglutinador de estas comunidades pronto dejaría ya de ser político y pasaría a ser cultural.

Palabras Clave: Transición, cultura, documental musical, nova cançó, música progresiva, rock urbano.

Abstract: The Madrilenian scene has remained in the collective memory as the clear evidence of the attainment of freedom of expression after the years of transition from dictatorship to democracy in Spain. However, before the eruption of this cultural phenomenon, some others had been appreciated in similar terms. The purpose of this article is to study three music documentaries: La nova cançó (1976), Canet Rock (1976) y Nos va la marcha (1979). This will allow us to see how, during the second half of the seventies, these musical phenomena that had erupted from the margins were considered to be places where to practice democracy in a real way; it will also remain clear how, with the gradual incorporation of the country to increasingly stringent dynamics of the consumer society, the unifying force within these communities would mutate from politics into culture.

Key Words: Spanish Transition, culture, music documentary, nova cançó, progressive rock, urbano' rock. 


\section{Por qué observar la producción cultural: la existencia de varias 'transiciones'}

Desde el fin del periodo denominado de transición política han aparecido numerosos estudios que se han acercado a esta etapa histórica con la intención de desentrañar algunas de las claves de la transformación que, en pocos años, asumió el país. Algunas de estas aproximaciones a la cuestión se han centrado en las decisiones adoptadas por los actores políticos durante dicha etapa, al considerarla consecuencia directa de estas; como indica Jaime Porras Ferreyra, "para estos autores, arribar a una democracia no es el resultado de un proceso de transformación en lo económico o en lo cultural sino el fruto de las relaciones entre las élites políticas, que realizaban reuniones y acuerdos con base a cálculos estratégicos" (2008: 91).

Sin embargo, a este tipo de aproximaciones se han sumado otras que contemplan la necesidad de ampliar la mirada e integrar a otros que, aun alejados del centro de poder (y, en ocasiones, quizá precisamente por ello), configuraron y promovieron un estado proclive al cambio en esos años.

Precisamente, el ámbito de la cultura se nos ofrece como uno de los espacios más interesantes a la hora de entender las diferentes "transiciones" que tuvieron lugar durante los años setenta y primeros ochenta en España ${ }^{1}$. No ya sólo porque la práctica cultural constituye un lugar de cristalización y promoción de una considerable variedad de mentalidades y actitudes gracias a su heteroglosia (Stam, 2001: 354), que permite la convivencia de mensajes acordes al orden hegemónico y de otros que lo contradicen; también porque la cultura constituyó durante esos años un síntoma de la eficacia de los procesos democratizadores del país.

Es esta última idea, junto con la intensa politización de la vida social durante los años de cambio sociopolítico en España, la que ha promovido, desde muy temprano, lecturas que ponían en relación diversos sectores culturales con las dinámicas sociopolíticas (un ejemplo de ello es VV.AA. [1986]). Sin embargo, no es hasta hace unos quince años que, de manera consciente y sistemática, se han explicado los años de la transición desde presupuestos que incluían de una manera determinante la actividad cultural. A este respecto, es obligado mencionar los estudios sobre las políticas culturales de la época emprendidos por los historiadores Carlos Mainer y Santos Juliá (Mainer, 2006; Mainer y Juliá, 2000) y por la estudiosa de la cultura Giulia Quaggio (Quaggio, 2014)², así como otros más específicos que indagan en las interacciones entre las lógicas del cambio político y determinadas instituciones de la cultura de masas

\footnotetext{
${ }^{1}$ Es sabido que las diversas esferas - política, económica, cultural- no tienen por qué coincidir ni en tiempos ni en formas, hecho señalado con gran acierto por Mainer y Juliá (2000: 81-85). En el caso que nos ocupa, por ejemplo, es necesario tener presente que los cambios en la sociedad y la cultura habían tenido lugar antes de la muerte de Franco. Como indica Pere Ysàs, "el crecimiento espectacular del turismo y la numerosa emigración exterior (...) comportó la familiarización de sectores relativamente amplios de la sociedad española con las formas de vida y con los valores sociales y culturales predominantes en las democracias europeas" (Ysàs, 2006: 29).

${ }^{2}$ Los modos de ambos de acercarse a la cuestión cultural son distintos; mientras que Mainer y Juliá optan por centrarse en la alta cultura, Quaggio lleva a cabo una aproximación más cercana a la de los estudios culturales.
} 
(Trenzado, 1999) ${ }^{3}$.

Es este tipo de aproximaciones, que amplían el marco de las narrativas de la Transición, las que nos guían en la tarea de observar el papel adoptado por determinadas expresiones culturales durante unos años en los que la cultura adoptó un papel determinante. Durante los años de la Transición, expresiones culturales como la literatura, el cómic, el teatro, el cine y la música vehicularon ideas de cambio, y es por ello que intentar desentrañar cómo eran y funcionaban en su contexto estas expresiones nos sirve para entender, en toda su complejidad, esta época intensa y dinámica ${ }^{4}$.

\section{Narrativas del cambio: mirar al pasado vs mirar al futuro ${ }^{5}$}

Los años de transición de la dictadura a la democracia fueron momentos de evidente revisión histórica. La visita a determinados momentos históricos que hasta entonces habían sido relatados de una manera única y dirigista o directamente desterrados de la versión oficial fue una labor necesaria para la consecución del cambio.

Los posicionamientos desde los que esta tarea se llevó a cabo fueron diversos. Algunos acercamientos apostaron por la continuidad y, en este sentido, se dedicaron a salvaguardar y actualizar, hasta donde era posible, los relatos que habían conformado el discurso franquista hasta esos momentos. Sin embargo, en mayor número, y especialmente a partir del proceso de renovación legislativa respecto a aspectos como la censura, aparecieron otros que se propusieron cuestionar los relatos legados. Su principal objetivo era desacreditar las narrativas sobre la historia impuestas por el régimen franquista y, a un mismo tiempo, centrar la atención en aspectos de la historia reciente del país que hubieran sido conscientemente tergiversados o desatendidos. Esta tarea implicaría la deconstrucción de los mitos y creencias promovidos por el régimen pero, también, la instauración de los momentos fundacionales y los nuevos actores de una renovada memoria colectiva ${ }^{6}$.

De manera paralela, y con mayor asiduidad según se hace más patente el cambio

\footnotetext{
${ }^{3}$ Pese a que su foco de atención se centra en el tardofranquismo (y el de el presente texto en los años del cambio político), el texto de Vicente Sánchez-Biosca sobre "Las culturas del tardofranquismo" resulta asimismo clave para entender los cambios sucedidos desde la muerte de Franco; como él mismo afirma: "en los años sesenta germinaron muchas de las claves culturales (...) que, sin incurrir en simplificaciones teleológicas, estallaron (es decir, se impusieron y extendieron entre la población) en los años eufóricos de conquista de las libertades" (2007: 109).

${ }^{4}$ Refiriéndose al cine, Palacio, por ejemplo, indica que este fue capaz de trasladar durante esos años "una nueva forma de ser y de sentir, y un cierto estado de conciencia favorable a las ideas que vertebran la transformación política: reconciliación social, recuperación de las libertades civiles y políticas, y descentralización del estado" (2011: 9).

${ }_{5}^{5}$ Para una mirada a las narrativas del cambio operadas en torno al cine documental de la época, acudir a Gómez Vaquero (2012).

${ }^{6}$ A este respecto, la incorporación a la vida política del país de exiliados políticos como, por ejemplo, Dolores Ibárruri, Santiago Carrillo y Josep Tarradellas tras su regreso a España implicó la puesta en marcha de diversas estrategias de "acomodación" de unas figuras que, durante décadas, habían permanecido excluidas no sólo del país sino también del discurso dominante. Para entender algunos de los procesos de reciclaje emprendidos durante los años de la Transición con respecto a Ibárruri, acudir a Benet (2013).
} 
político, se emprende una labor de observación y problematización de lo que está sucediendo en los diversos ámbitos durante esos años. La conciencia de estar viviendo un momento excepcional incita a los medios a ocuparse de cada uno de los distintos sucesos que parecen jugar un papel determinante en la nueva etapa que está atravesando el país. Junto a las miradas críticas al proceso (que las hubo), surgieron otras que se planteaban en términos más optimistas respecto al cambio.

El resultado de todo esto es la presencia en los medios de determinados eventos y personajes que, considerados como epítomes de lo que está ocurriendo en el país, adquieren una visibilidad inédita. A lo largo de la segunda mitad de los años setenta, determinados fenómenos culturales llegarían a ser definidos como manifestaciones de la libre expresión, ya hubieran surgido como un ejercicio de resistencia en un contexto poco permeable (el caso de la nova cançó, ligada a la lucha catalanista y antifranquista), ya constituyeran espacios de libertad semejantes a los existentes en los países democráticos occidentales (los festivales de rock progresivo) o incluso se plantearan en términos de la incorporación del país a las dinámicas del capitalismo (el rock urbano, que busca abandonar los márgenes de una industria deficiente). Más allá de las particularidades, estos fenómenos anunciaron algunos de los elementos que serán básicos en la conformación de una identidad nacional basada en la modernidad que ya desde comienzos de los años ochenta será habitual.

Las generaciones del cambio: la juventud y los festivales como vanguardia de la transformación social

Un artículo de la revista $\mathrm{La} \mathrm{Calle}^{7}$, publicado en noviembre de 1978 en la sección de "Sociedad. Jóvenes", describe una nueva generación de jóvenes que, con 15 años, están "de vuelta de todo". Pertenecientes a "la generación del rollo, de la píldora, el porro y el "psé', que sueltan a la menor de cambio", son retratados como "chicos de barrio" que "creen en el amor, en la amistad y no en la política" y para quienes la guerra civil es "agua pasada que los mayores suelen esgrimir como amenaza del "cómete eso: en la guerra, tu padre y yo lo pasamos muy mal"' (Claret y Luzan, 1978: 30, 31).

La prensa se acercaba de manera ambigua a estos miembros de una nueva generación que, con un argot propio y una tendencia al "pasotismo", parecía renegar del pasado y desconfiar del futuro. Pese a que el tono empleado en las crónicas y referencias fue variado, la mirada sobre estos nuevos jóvenes tendió a relacionarlos con el desencanto (político) que, según los medios, se había esparcido en parte de la sociedad española, desilusionada con los resultados del cambio político iniciado años antes. En ocasiones, se les achacó una actitud acomodaticia y renuente al cambio, al

\footnotetext{
${ }^{7}$ Revista surgida en 1978, fundada por un grupo de periodistas procedente de la conocida y por entonces en crisis Triunfo, autocalificada como "la primera a la izquierda" y conformada por, entre otros, César Alonso de los Ríos, Fernando Lara, Carlos Elordi, Antonio Elorza, Julia Luzán y, durante un tiempo, Manuel Vázquez Montalbán.

${ }^{8}$ El término 'pasota' aparecerá en la prensa desde finales de los años setenta para designar al miembro de una joven generación caracterizada por encontrarse al margen de la vida política y de las reivindicaciones sociales.
} 
estilo de los términos empleados por el periodista Carlos Luis Álvarez "Cándido" en un artículo de opinión sobre esta nueva generación de jóvenes coincidentes con la promulgación de la Constitución española:

Los pasotas son los gaiteros del desfile reaccionario, van delante. Sus formas aparecen vacías de toda intención histórica, porque, en el mejor de los casos, su utopía, que nace de la contraposición entre el mundo que es y el que debiera ser, es la de suspender todo pensamiento, como si el mundo, fatalmente, 'fuese destruyéndose a sí mismo' (Cándido, 1980: 121) .

Más allá del tono empleado, lo que estas alusiones evidenciaban era la consideración de esa nueva generación como producto y síntoma de los cambios sucedidos en esos pocos años ${ }^{10}$ : los integrantes de esa recién llegada generación de jóvenes, algunos de los cuales aún no alcanzaban su mayoría de edad durante los últimos años de la década de los setenta, conformaban una nueva actitud ante la vida que bien podía relacionarse con la nueva situación del país.

La consideración de la juventud en relación al cambio operado en los ámbitos político, económico y social no era algo nuevo; como tampoco lo era la consideración de los espacios específicamente creados para ella como síntomas y dinamizadores del cambio. Desde mediados de los años setenta, si no antes, en cierta prensa de carácter progresista se consideraría, por ejemplo, ciertos festivales de música como lugares en los que ejercer una libertad de expresión inexistente en otras esferas de la vida social ${ }^{11}$. En dichas crónicas, se insistía en el carácter abiertamente lúdico de unas jornadas en las que parecían darse las condiciones adecuadas para la consecución de la soñada democracia:

El pasado fin de semana, en Canet de Mar, se celebró la octava edición del Festival de Canción, llamándose por primera vez de una forma distinta a las anteriores y clásicas de Sis Hores de Cançó (Seis Horas de Canción). Por primera vez también, en Canet, se incorporó decididamente el ingrediente festivo, que se inició con una verbena popular el viernes por la noche, con final quemado con ron en una madrugada playera. Por primera vez también, todos los actuantes en Canet cobraron por igual, haciendo reparto de

\footnotetext{
${ }^{9} \mathrm{El}$ periodista aclaraba poco después: "no niego al «pasotismo» una realidad material y sociológica. Lo que sí niego es que los hábitos y costumbres de esa juventud puedan quebrantar y menos cambiar las normas sociales que rechazan" [Cándido, 1980: 121]).

${ }^{10}$ La consideración de la juventud como un epítome de cambios estructurales en los medios fue ya señalada por John Clarke, Stuart Hall, Tony Jefferson y Brian Roberts en "Subcultures, Cultures and Class: A Theoretical Overview", publicado originalmente en 1975 como Working Papers in Cultural Studies 7/8, compilado al año siguiente por Hutchinson y reeditado después por Stuart Hall y Tony Jefferson en el libro Resistance Through Rituals: Youth Subcultures in Post-war Britain (Routledge). Hay traducción del libro al español con el título de Rituales de resistencia. Subculturas juveniles en la Gran Bretaña de postguerra (Madrid: Traficantes de sueños, 2014).

${ }^{11}$ En realidad, los festivales de música pop habían aparecido bastante antes. En concreto, son de reseñar los festivales que, al estilo de los franceses, se desarrollaron en el Circo Price de Madrid desde el 18 de noviembre de 1962, cuando se celebra el Primer Festival de Música Moderna; en él actuaron grupos como Dick y Los Relámpagos, Los Tonys, Los Pekenikes y Los Estudiantes. Para más información acerca de esta cuestión, acudir a Rodríguez "Rodri”" (1999: 387-393).
} 
beneficios. Posiblemente, éste haya sido, en todos los sentidos, el primer Canet de la democracia (Batista, 1978: 28).

Más allá de la consideración de estos eventos colectivos como simples lugares de esparcimiento, se les distinguía una capacidad para visibilizar determinadas actitudes y expresiones contraculturales ${ }^{12}$. Es la capacidad de congregación y convivencia, asî como la participación activa de los asistentes lo que confería a esta reunión un cariz inédito, ausente en otro tipo de productos culturales. Así lo consideraba Manuel Vázquez Montalbán, en referencia a las Sis Hores de Cançó celebradas en Canet de Mar el verano de 1975:

[El cantante] Pi de la Serra dio el toque final a una fiesta democrática cuyos principales protagonistas ya no eran los cantantes. Era un público vital, concienciado, que daba un definitivo sentido histórico a un acto que podía haber empezado y terminado como una manifestación más de poder juvenícola y que, en cambio, había ido más allá y se había convertido en un delirante testimonio democrático con música y letra (Vázquez Montalbán, 1975:19).

Frente a los espacios que el régimen franquista había creado para el esparcimiento controlado de una juventud cada vez más interesada en dinámicas similares a las disfrutadas por las juventudes de los países democráticos y a la ausencia de un reconocimiento real de las necesidades de este sector de la sociedad ${ }^{13}$, estos lugares se presentaban como islas en las que ensayar lo que una parte de la población reclamaba: la libertad de expresión.

Es con el objetivo de captar esos lugares excepcionales que surgen de manera temprana los primeros testimonios audiovisuales sobre festivales musicales. Ya sea en forma de homenaje a aquellos que se lanzaron (y aún continuaban haciéndolo) a promocionar estos espacios para la expresión de sentimientos críticos con la oficialidad (La nova cançô), de testigo fehaciente y lúdico de las extraordinarias condiciones en las que tienen lugar esos encuentros colectivos (Canet Rock) o de acto de afirmación de una expresión cultural dejada de lado por una industria aún por hacer y que ya se anuncia como polarizada (Nos va la marcha), estas películas pretendieron visibilizar una serie de lugares que, desde los (distintos) márgenes, modificaban una realidad social que en absoluto era monolítica.

Su análisis nos proporcionará nuevas claves para identificar los términos en los que eran referidas estas manifestaciones culturales y nos permitirá comprobar cómo ya, durante la segunda mitad de los años setenta, existían unas comunidades culturales

${ }^{12}$ A este respecto, Eduardo Haro Ibars y Marcelo Covián afirmaban respecto al Canet Rock de 1975: "Canet no ha sido una casualidad; ha sido el producto natural y necesario de un mundo social existente que debía y debe encontrar medios de expresión multitudinarios e individuales" (1975: 27).

${ }^{13}$ Tal y como indica José Ignacio Cruz, las medidas asumidas por el régimen durante la década de los sesenta con la intención de reorientar las políticas relativas a la juventud puestas en práctica hasta entonces en un deseo por satisfacer a una nueva juventud no implicaron una modernización significativa (2003-2004: 199). 
articuladas en torno a estos fenómenos musicales que se posicionaban de manera crítica respecto al statu quo; así cómo, con la progresiva incorporación del país a las cada vez más estrictas dinámicas de la sociedad de consumo, el elemento aglutinador pronto dejaría ya de ser político (la oposición al franquismo) y pasaría a ser cultural (la pertenencia al ámbito underground).

\section{La cultura como reivindicación política. La nova cançó (Francesc Bellmunt, 1976)}

En julio de 1975 tiene lugar una nueva edición del festival Sis Hores de Cançó en Canet de Mar, Barcelona ${ }^{14}$. En él actúan artistas como Teresa Rebull, Marina Rosell, María del Mar Bonet, Ovidi Montllor, Rafael Subirats y Pi de la Serra, entre otros.

Tal evento tendrá un registro documental en la película realizada por Francesc Bellmunt, con la participación en el guión del periodista musical Ángel Casas, quien también llevará a cabo las entrevistas. Sin embargo, el film, de título La nova cançó, no se plantearía como un simple registro de lo acaecido en este evento, sino que pretenderá dar constancia de la magnitud de un fenómeno que, ya desde sus comienzos, había sido interpretado desde presupuestos que trascendían los estrictamente musicales. Concebida como un acercamiento a este fenómeno musical surgido a finales de los cincuenta y con proyección nacional e internacional desde los sesenta, la película llevará a cabo un homenaje a la nova cançó como expresión cultural capaz de movilizar y dar voz a determinados sentimientos políticos de carácter nacionalista.

Así se plantea ya desde un comienzo: junto a los títulos de crédito iniciales y con una melodía de guitarra sonando de fondo, se suceden diversas imágenes en las que, entre la multitud, se destacan aquellos asistentes al evento que, ya sea paseando en grupo, sentados o echados en el césped, llevan señeras, barretinas y bandas con la bandera catalana en la frente. A partir de estas imágenes introductorias, se irán alternando dos tipos de escenas que también contribuirán a identificar a la nova cançó con la reivindicación nacionalista: unas corresponden a las actuaciones más significativas de algunos de los representantes de la nova cançó, tenidas lugar dentro y fuera del festival; las otras están dedicadas a interrogar a diversos personajes de la industria musical, la cultura y la política catalana sobre el fenómeno.

Con respecto a las primeras, a lo largo del film hacen su aparición varios intérpretes de la cançó: Francesc Pi de la Serra, quien convenientemente abre la película tras los títulos de crédito cantando La cultura (que, como dice la letra, "es una palabra delicada, tan peligrosa como la dinamita" y que, además, rima "con futura apertura y dictadura"); Jaume Sisa, que interpreta la popular Qualsevol nit pot sortir el sol ante un auditorio vacío en la sala Zeleste ${ }^{15}$; Ramón Muntaner, cantando Cançó de

\footnotetext{
${ }^{14}$ La primera edición tuvo lugar en 1969, donde actuaron en el Tennis Club de Canet de Mar Lluís Llach, Ovidi Montllor y Francesc Pi de la Serra. Tras ésta, se celebrarían otras en años sucesivos. ${ }^{15}$ La sala Zeleste fue uno de los primeros espacios de conciertos habituales en Barcelona y desde 1973 jugaría un papel importante en la difusión del rock progresivo en la ciudad. Gómez-Font (2011:86)
} 
carrer en Prats de Lluçanés ${ }^{16}$; La Trinca, que, ataviados con chándals, interpretan Botifarra de pagès en pleno Estadio del Futbol Club Barcelona ${ }^{17}$; Ia \& Batiste, quienes cantan Sifòn en un escenario improvisado; Ovidi Montllor interpretando La fera ferotge en Prats de Lluçanés; el cantante de las Islas Baleares Uc, cantando ante la cámara La presó de Nàpols; M. ${ }^{a}$ del Mar Bonet con Abril, en L’Hospitalet de Llobregat; Lluis Llach en el Palau dels Esports de Barcelona, interpretando L'estaca; Pere Figueres, que canta Pres d'aquest país sóc; Rafael Subirachs y su Catalunya comtat gran, basada en el romance del siglo XVII Els segadors, en el Sis Hores de Cançó en Canet de Mar; Pau Riba, tocando una versión eléctrica de Noia de porcellana; y Raimon en el Palau dels Esports, con la popular -aunque apenas interpretada en directo por motivos de censura- Jo vinc d'un silenci.

Como hemos indicado, a estas actuaciones se le suman entrevistas a diversas personalidades de la cultura catalana como, por ejemplo, Joan Miró, que insiste en que el poder de la cançó catalana reside en su capacidad para ser directa, y Salvador Espriú, que reflexiona acerca de la relación entre el poeta y la música; pero también, a aquellos que han colaborado de alguna manera a la difusión de esta expresión musical, como el periodista Manuel Vázquez Montalbán, quien encuentra la razón de su éxito en el apoyo que ésta ha recibido de una burguesía catalana interesada en esta expresión de la lengua propia y conocedora de la canción francesa, Claudi Martín, por entonces director de la Editora General Societat Anònima Edigsa ${ }^{18}$, y algunos de los intérpretes que después realizarán su actuación (el caso de Lluis Llach, Pau Riba y Raimon); y, por último, también a figuras que han colaborado de manera activa a la conservación y defensa de la identidad catalana como, por ejemplo, Jordi Puyol (quien indica la importancia de las capas mixtas de la sociedad en la promoción de manifestaciones que reafirman la identidad catalana), el que fuera fundador del Partido Socialista del País Valenciano (PSPV) en 1962, Vicent Ventura, y hasta el carismático futbolista del Barça Carles Rexach.

Ambos tipos de escenas cumplían el objetivo principal del film: evidenciar la existencia de una cultura catalana consistente. Ésta se encontraba así pues representada por distintas personalidades que acreditaban la existencia (y resistencia) de una cultura propia que tenía su mejor representación en esos recientes y reconocidos intérpretes del ámbito de la música que aparecían en el largometraje interpretando algunos de sus éxitos. Pero también evidenciaban el alcance de un fenómeno que, teniendo su foco principal en Barcelona, se había expandido con relativa facilidad a los lugares adyacentes, tal y como lo evidenciaban las diversas secciones dedicadas en la película a

\footnotetext{
${ }^{16} \mathrm{La}$ actuación forma parte del recital que dieron Muntaner y Ovidi Montllor dentro de las fiestas de los quintos de 1975 de Prats de Lluçanés. Los intérpretes de la nova cançó no se limitaban al circuito de locales musicales, más específicos, sino que actuaban en todo tipo de eventos.

${ }^{17}$ El nombre de Estadio del Fútbol Club Barcelona nació en 1965 tras consulta a los socios, sustituyendo al de Estadio del Club de Fútbol Barcelona, empleado desde su inauguración en 1957. La denominación Camp Nou, como también se le conocía popularmente no se oficializaría hasta la temporada 2000/2001, tras nueva consulta a los socios.

18 Tal y como se indica en Gómez-Font (2011: 31), el primer disco de cançó que saca Edigsa al mercado es Espinàs canta a Brassens (1962), de Josep Maria Espinàs.
} 
la cançó en los Països Catalans ${ }^{19}$ en España (el País Valencià, Les Illes Balears, Andorra y Catalunya Nord). Asimismo, la presencia de los diversos lugares en los que tenían lugar las diferentes actuaciones (desde escenarios improvisados, a salas específicas y grandes auditorios -en los que, por ejemplo, tienen lugar las actuaciones de Lluis Llach y Raimon en la parte final de la película-) certificaba la aceptación de una expresión que ha conseguido imponerse frente a las cortapisas del gobierno franquista.

La consideración de esta expresión musical como un acto antifranquista era señalado por algunos de los testimonios incluidos en la película, que indicaban la posibilidad (o necesidad) de entender este tipo de recitales como mítines políticos; una interpretación que por entonces se llevaba a cabo ya de manera habitual, tal y como lo atestiguan los contraplanos de la respuesta del público en las actuaciones más multitudinarias incluidas en esta última parte de la película ( $L$ ’estaca de Lluis Llach, Catalunya Comtat Gran, de Rafael Subirachs, y Jo vinc d'un silenci, de Raimon, que significativamente cierra el film) ${ }^{20}$.

Y es precisamente esta interpretación la que, al decir de una crítica de la época, debían de hacer los asistentes que acudieron a la proyección del film en una sala de cine de Barcelona. Al menos así lo constata la siguiente crónica del estreno de la película en junio de 1976, aparecida en Diario de Barcelona:

Fuertes aplausos saludaron la aparición, en el principio, de banderas catalanas en el festival de Canet, y volvieron a sonar cuando Pi de la Serra cantó La cultura; Qualsevol nit portir el sol, de Sisa, fue seguida con mucha atención y coreado su estribillo [...]. El siguiente motivo de regocijo fue la alusión al 5-0 del Barça, cantado por La Trinca, con chándal y en pleno césped del Nou Camp. La aparición de cada cantante era invariablemente aplaudida, pero Ovidi Montllor, con su Fera ferotge, hizo subir los decibelios. [Se apreció] la ascensión de Subirachs, con su excelente interpretación de Els segadors, acompañada con palmas por todo el gallinero [...]. Las salvas finales de aplausos las cosecharon [el luchador antifranquista y procatalanista] Lluís M. Xirinachs y Raimon cuando aquel apareció levantado en hombros por el público del Palacio de los Deportes y este cantó Jo vinc d'un silenci, canción escogida con muy buen tino por los realizadores. Verles a ambos en pantalla era poco menos que surrealista. Quizá así se explica el vuelco del público, directo y sin manías, hacia $L a$

19 Precisamente, el término había sido popularizado por los ensayos de 1962 Nosaltres, els valencians y Qüestió de noms, escritos por uno de los entrevistados que aparecen en la película, Joan Fuster.

${ }^{20}$ En esta última parte del film, a las actuaciones de Llach y Subirachs, y antecediendo a la de Raimon, que es ya de cierre, le sigue la de un Pau Riba que, por su apariencia (maquillado, con un pequeño pañuelo al cuello), parece más bien un cantante glam; además, en vez de la guitarra española, se presenta acompañado de dos guitarras (una la porta él), batería, saxofón y percusión. Su presencia en la película resulta así una disonancia (también en el sentido musical) que viene a atestiguar la deriva que algunos de los músicos que comenzaron su andadura musical ligados a la nova cançó tomarían hacia cauces más heterodoxos; así lo certifican también sus palabras en la entrevista previa a su actuación: a la pregunta de: "CCrees que ayudas a la cultura catalana?", responde que sí, "destruyéndola". 
nova cançó; es la magia de la sensación de ver a la realidad cotidiana reincorporarse a otro medio de comunicación (Jaraba, 1976: 21).

Lo cierto es que el estreno de la película de Bellmunt, casi un año después de la celebración del festival, se llevó a cabo en un contexto que favorecía semejante respuesta del auditorio: en el seno del Congrés de Cultura Catalana, celebrado en Montjuïc entre los años 1975 y 1977, que comprendía como su objetivo principal reivindicar y reforzar la cultura catalana en sus diversas manifestaciones tras un largo periodo de 'anormalidad'21.

Es así como la película (al igual que el movimiento musical del que se ocupa y el festival sobre el que centra su metraje) movilizó sentimientos ligados a la reivindicación política doblemente: a través de la presencia (y homenaje) de aquellos que forman y han formado parte de la expresión de la cultura catalana; y mediante la constancia de su propia visibilidad. Respecto a este último aspecto, hay que tener presente que La nova cançó es, junto con la película La ciutat cremada (Antoni Ribas, 1976), el primer largometraje filmado y estrenado en catalán; la película certificaba el cambio sucedido en relación a uno de los aspectos que serán considerados como de mayor relevancia de la reivindicación catalanista (y que ligaría a la nova cançó con la película documental): el uso público de la lengua propia22.

\section{La cultura como lugar de libertad. Canet Rock (Francesc Bellmunt, 1976)}

Frente a la evidente reivindicación en pro de la cultura catalana presente en $\mathrm{La}$ nova cançó, el documental que Bellmunt y Casas realizaron en momentos coincidentes, de título Canet Rock, posee un carácter menos específico.

La película se concibió como un acercamiento en exclusiva a la edición del 26 y 27 de julio de 1975 del festival celebrado en paralelo a Sis Hores de Cançó en Canet de Mar, de nombre Canet Rock, donde se aglutinarían grupos y cantantes que, por resultar más heterogéneos, no tenían cabida en el dedicado a la cançó. Sin embargo, esta exclusividad no sería la única diferencia entre ambas propuestas: si en La nova cançó el foco se dirigía principalmente a los ejecutantes de dicho fenómeno musical y a aquellas figuras significativas que podían interpretarlo como una manifestación más de la reivindicación catalanista, en Canet Rock la atención se centra en las actuaciones del evento, pero también, y de manera mucho más significativa que en La nova cançó, en aquellos que han acudido a participar en este acontecimiento colectivo. Es así que el largometraje da cuenta no sólo de la existencia la música progresiva en España ${ }^{23}$ a

${ }^{21}$ El manifiesto surgido de Congrés de 1977 se encuentra disponible en la página de la Fundación del Congrés de Cultura Catalana.

${ }^{22}$ La implantación del decreto ley sobre las lenguas regionales el 31 de octubre de 1975 derogó la orden ministerial del 23 de abril de 1941 que había prohibido la proyección cinematográfica en otro idioma que no fuera el español.

${ }^{23}$ En realidad, la música progresiva había surgido a finales de los años sesenta (la aparición del grupo Máquina! en 1969 es un hito a este respecto), si bien no es hasta mediados de los setenta cuando, con la aparición de diversos festivales locales, alcanza una visibilidad mayor. Su foco principal lo tendría en Barcelona, pero Sevilla sería también otro de los focos más importantes. Para más información, acudir a Turtós (1995: 75-81). 
través de las actuaciones de Orquesta Platería, Barcelona Traction, Jordi Sabatés, Gualberto, Fusioon, Iceberg, Lole y Manuel, Pau Riba, Orquesta Mirasol, Grup Eina, Ia \& Batiste y Companya Electrica Dharma, sino también de una juventud con su propia manera de acercarse a él y que aparece de manera habitual en pantalla.

Realizada al estilo del cine directo practicado previamente en documentales musicales sobre festivales como Monterey Pop (Donn Alan Pennebaker, 1968), Woodstock (Michael Wadleigh, 1970) y Gimme Shelter (Albert y David Maysles y Charlotte Zwerin, 1970)24, la película de Bellmunt trasladaba, como éstas, la experiencia de dichos eventos; pero también evidenciaba la intención de representar una generación de jóvenes que, aglutinados en torno a un acontecimiento concreto, podían satisfacer y compartir sus inquietudes en un espacio que, como indicaba uno de los asistentes entrevistados para la película, se podía equiparar a "una lata de conservas: libertad provisional en un espacio provisional, pero prometedor de futuro; es un futurible".

En La nova cançó, los contraplanos correspondientes al público asistente a las actuaciones (planos) se reducían a las ocasiones en las que el tema interpretado tenía una marcada carga simbólica, como el caso de L'estaca, Catalunya comtat gran y Jo vinc d'un silenci (que, como hemos visto en el apartado anterior, se encontraban además presentes en la parte final del documental). Sin embargo, en Canet Rock, los asistentes tienen, desde un primer momento, un mayor protagonismo; esto es así hasta el punto de que, en determinadas escenas, la actuación del grupo correspondiente quedará en fuera de campo, permaneciendo únicamente la música en directo como acompañamiento a las actitudes de los asistentes mostrados en la banda de imagen (es el caso, por ejemplo, de la actuación del grupo Barcelona Traction) ${ }^{25}$.

La presencia de esta nueva generación en pantalla es predominante durante toda la primera mitad del largometraje y en la actuación final. Además, estos se muestran de manera más acusada en su singularidad al haberse empleado planos más cercanos que los peculiarizan dentro de la masa concurrente. Se muestran así sus gestos, su manera de vestir, sus actitudes y su forma de bailar, mientras en algún momento las fuerzas del orden, representadas por guardias civiles, observan el desarrollo del evento con curiosidad e incluso, como corrobora una de las escenas, esbozando una sonrisa ante el paso de una joven en bikini acompañada de otras dos (mientras en la banda sonora se escucha de fondo la actuación correspondiente). Es de este modo que se dibuja un espacio de permisividad inédito donde no sólo se acude a escuchar música, sino también a poner en práctica todo tipo de actividades lúdicas (como dice una chica sentada en la playa, "me he emborrachado... he dado vueltas, he encendido candelas, me he desnudado y además he visto el festival").

Tal y como las críticas de la época indicaban, Canet Rock certificaba la

${ }_{24}$ En las críticas aparecidas tras su estreno sería oportunamente comparada con el conocido documental musical Woodstock -como también los festivales, incluido el realizado en Canet, serían comparados con los celebrados en Estados Unidos y Reino Unido.

25 También hay que señalar que este tipo de música, caracterizada por ser instrumental y por tratarse de temas largos, favorecía este tipo de operaciones. 
existencia de espacios al margen de la represión y la censura ${ }^{26}$. La película daba cuenta de una actividad que, pese a las dificultades, se hizo posible. Es quizá el deseo de apoyar esta iniciativa lo que llevó a los responsables del film a situar como escena de apertura la actuación improvisada de Sisa, cuya participación en el festival había sido prohibida y que, sentado en la explanada donde había tenido lugar el festival, a plena luz del día y entre los pocos asistentes que aún quedaban entre los desperdicios tras los excesos de la noche, interpreta La primavera i l'estiu.

Resulta significativo que, en términos generales, la informalidad, tanto del público que acudió al festival y se expresó ante la cámara como de la película, fue en general valorada positivamente por la crítica como una manera nueva de expresarse, ajena a la represión existente hasta entonces, pero también de hacer cine (documental). Asimismo, la circunstancia de proyectarse una película como ésta, que no había sido filmada en el formato oficial (se había realizado en $16 \mathrm{~mm}$ ), fue también celebrada por parte de la prensa como un paso más hacia la diversificación propia de un Estado democrático $^{27}$. La evidencia de sucesos como estos (la celebración del festival y la proyección de la película) parecía certificar la posibilidad real de ese "futurible" apuntado por uno de los entrevistados en el film.

\section{La cultura como industria. Nos va la marcha (Manuel Gómez Pereira, Raimundo García Fernández y José Manuel Berastegui Rubio, 1979)}

Poco más de tres años después de la primera edición de Canet Rock, el 22 de septiembre de 1978 se celebra en la plaza de toros de Vista Alegre, en Madrid, el festival Rocktiembre, celebrado con la intención de recaudar fondos para el autogestionado Sindicato de Músicos de Madrid. En él actúan grupos como Mad, Topo, Teddy Bautista, Cucharada y Leño, pertenecientes a lo que se denominaba "rock urbano" o "rock bronca", un movimiento musical con Madrid como punto neurálgico, caracterizado por el autodidactismo y el do-it-yourself.

Contagiados de este espíritu, tres jóvenes (Gómez Pereira, García Fernández y Berastegui) filmarían las actuaciones del festival Rocktiembre 78, así como varias entrevistas a promotores de este tipo de música; en concreto, a: Mariscal Romero, responsable de varios programas dedicados al rock emitidos por la emisora de onda media Radio Centro y precursor del mítico sello discográfico Chapa; Teddy Bautista, líder de Los Canarios en los años sesenta, que después conectó con la música progresiva y que en esos momentos se encuentra ligado a los grupos de rock urbano; el locutor del programa en Onda 2 FM de Radio España Champú, peine y brillantina y Dinamita, Rafael Abitbol; y Jesús Ordovás, director y presentador de programas

\footnotetext{
${ }^{26}$ Parte de estos espacios, vinculados a la música, están también representados en el film: en un momento de la película, la cámara pasea por los puestos en los que se venden, entre otras cosas, las revistas alternativas Star(de historietas) y Vibraciones (musical).

${ }^{27}$ J. E. Lahosa, por ejemplo, afirmó: "Para la historia industrial «Canet Rock» es el primer film de $16 \mathrm{~mm}$ que consigue carnet oficial de exhibición sin acudir a la trampa siniestra del «hinchado» al formato mínimo reconocido de $35 \mathrm{~mm}$. Esta circunstancia abre posibilidades a unos planteamientos de producción y distribución hasta ahora inabordables y de indiscutible interés" (1976).
} 
musicales en la misma emisora entre 1975 y 1979 y colaborador de las revistas Triunfo, Ajoblanco, Disco-Express y Vibraciones, entre otras.

Por una parte, Nos va la marcha pretende contrarrestar la ausencia de alusiones (o la presencia de alusiones negativas) al rock urbano en los medios mayoritarios ${ }^{28}$. Pues no son los medios consolidados los que apoyaban a este tipo de manifestación musical, sino un grupo de individuos que se van abriendo camino en los diversos ámbitos de la pseudoindustria y que, como los grupos a los que patrocinan, aprovechaban los espacios que el sistema no era capaz de cubrir para desenvolverse, ajenos (para bien y para mal) a las leyes de un mercado que en España iba afectando a todos los ámbitos de la vida cultural.

Por otra, y más allá del registro de un evento que apenas recibiría la atención de los medios, el largometraje pretende constatar la existencia de este conglomerado musical surgido al margen de la industria mayoritaria y denunciar, gracias a la presencia de los entrevistados, la dificultad que estos grupos tienen para situarse en una industria insuficiente y cada vez más polarizada. Así lo indica, por ejemplo, Teddy Bautista en la entrevista que precede a las imágenes de su actuación en el festival: el principal problema que se les ha presentado a la hora de llevar a la práctica esta iniciativa surgida de algunos de los grupos que forman parte de la programación ha sido, junto a la falta de experiencia, la necesidad de inventar una infraestructura inexistente.

Logradas con esfuerzo y satisfacción las libertades reclamadas, ahora queda la puesta en marcha de una política cultural que contemple la inserción de todo tipo de expresiones culturales a través de la creación de infraestructuras. Así pues, las reivindicaciones adquieren otro matiz -lo que no implica que tengan implicaciones políticas: es bien sabido que la hegemonía cultural se define en términos económicos y políticos-. Los defensores y difusores de este nuevo tipo de música presentes en la película reivindican la creación de cauces que permitan la integración de las manifestaciones culturales surgidas en los márgenes de la hegemonía cultural.

Sin embargo, es precisamente la inexperiencia y el amateurismo que caracterizaban al rock urbano en esos momentos, fruto de ese posicionamiento (involuntario) al margen, los que, al parecer de algunos de sus defensores, dotaban de crédito a esta expresión musical. La modestia en el alcance y el localismo que ha caracterizado al rock urbano hasta entonces ${ }^{29}$, y que denuncian de manera continua los

\footnotetext{
${ }^{28}$ En estos momentos aparecían en la prensa mayoritaria artículos en los que se denunciaban las perniciosas condiciones en las que se desarrollaban estos eventos (ver Costa, 1978: 60). Sin ir más lejos, la crónica del festival aparecida en el diario El País, así lo hacía: "El pasado viernes tuvo lugar un Festival de rock en Madrid. En una plaza de toros. Y hubo violencia. Los festivales de rock se desarrollan en polideportivos, campos de deporte, frontones, campos de fútbol o plazas de toros. Hasta el más negado puede encontrar una relación simbólica entre el marco y la violencia y agresividad que se desarrollan en torno al mismo" (M. C., 1978: 32).

${ }^{29} \mathrm{El}$ rock urbano surge en Madrid, ciudad a la que se referirán varias canciones; en el documental, sin ir más lejos, se incluyen dos temas que hacen alusión a la ciudad: Vallecas 1996, por Topo, y Este Madrid, de Leño. La cuestión del espacio geográfico resulta interesante respecto a cómo ésta moldea una identidad colectiva determinada; queda esta cuestión pendiente para sucesivos estudios
} 
participantes en el documental, permite de manera paralela a los entrevistados construir argumentos de defensa relacionados con la autenticidad. Al menos así parecía desgranarse de las palabras del entrevistado Mariscal Romero, quien establecía una dicotomía entre la música underground (considerada como buena música) y la música comercial (apreciada como mala por encontrarse bajo los dictados del mercado); al tiempo que aludía, en términos esperanzadores, a la llegada de gente joven a la radio que, como él mismo, por encontrarse ajena a la manipulación de las grandes discográficas, podía identificar y apoyar de manera más clara este tipo de música.

Más allá de impresiones concretas, son evidentes los términos en los que se valora y contextualiza esta expresión musical frente a las anteriores abordadas en el presente texto: la reivindicación se emprende ahora desde presupuestos estrictamente industriales.

La consecución de un espacio más plural donde tengan cabida las manifestaciones surgidas al margen de la hegemonía cultural (e industrial) tendrá su manifestación más fehaciente poco tiempo después, cuando una gran cantidad de músicos (pero también pintores, diseñadores de moda, dibujantes de cómic y cineastas jóvenes), que han desarrollado una corta trayectoria con los medios que tenían a su alcance, accedan a espacios que hasta entonces habían estado reservados a otro tipo de manifestaciones culturales. Por entonces, los grupos de rock urbano, conformados por jóvenes que luchaban por hacerse un hueco en la música, practicaban el autodidactismo y representaban la consecución de una nueva época quedarán desdibujados en un conglomerado que hace gala de su modernidad ${ }^{30}$. Pero eso ya es otra historia...

\section{Transición cultural: de la reivindicación política a la industrial}

En plena eclosión de la Movida madrileña (1983), un artículo acerca del fenómeno de los conciertos de rock se expresaba en los siguientes términos:

Desde la desaparición del anterior jefe del Estado hasta nuestros días, los conciertos de rock and roll se han ido convirtiendo en las manifestaciones populares por excelencia. En pocas ocasiones, como en los espectáculos citados, el pueblo llano y sencillo ha conseguido adueñarse de su propio terreno, desinhibiéndose de buena parte de las frustraciones cotidianas, vistiendo aunque solo sea durante unas horas de la mejor forma imaginada, fumando lo que apeteciera aún antes de la despenalización del hachís, magreando descaradamente a la persona amada o a la recién conocida. Los conciertos de rock han sido las auténticas fiestas de la transición política y ello pese a los organizadores, pese a las casas de discos y, con frecuencia,

donde se contemple la puesta en relación de la geografía (simbólica) y la expresión musical que, en el caso de la nova cançó, la música progresiva y el rock urbano resultan evidentemente interesantes. ${ }^{30}$ Ello coincidirá además con la práctica desaparición del cine documental en los medios (en parte por la disminución en la producción tras la entrada en vigor del Real Decreto 3304/1983, de 28 de diciembre conocida popularmente como Ley Miró). 
pese a la crítica (Harguindey, 1983: 69) ${ }^{31}$.

Sin embargo, es precisamente la consideración de los festivales y conciertos de rock como un fenómeno con importantes implicaciones socioculturales la que llevó a que ciertas críticas, tras su estreno en el Cine Dúplex de Madrid el 12 de mayo de 1979, echaran en falta en Nos va la marcha la presencia del "protagonista principal del «rollo»": el público (Bueno, 1979)32. Lo cierto es que la ausencia de esa parte receptora en el film bien pudiera ser indicativa de la perspectiva adoptada para acercarse a este fenómeno en la película: ya no se pretende mostrar cómo un tipo de música sirve de espacio para la expresión de nuevas conductas, sino, sobre todo, reivindicar la necesidad de que dicho fenómeno underground, y por ello considerado como espontáneo y auténtico, pueda integrarse en una industria musical cada vez más polarizada.

En La nova cançó, el deseo de homenajear una determinada práctica cultural se inserta dentro de la reivindicación de tipo político y, en concreto, nacionalista; el fenómeno de la cançó en Catalunya ya había trascendido lo meramente musical, y la película contribuyó a convertir dicho fenómeno en un epítome de la reivindicación nacionalista (tal y como quedará después en la memoria colectiva). Por su parte, en Canet Rock, la certificación de la existencia del festival como un espacio de libertad sirvió para reclamar la generalización de dicha condición en el resto del país; esto se hizo principalmente a través de la presencia de aquellos que, junto a los intérpretes de la música progresiva, serían también protagonistas de la película: los asistentes ${ }^{33}$. Por último, en Nos va la marcha, la atención al fenómeno del rock urbano tiene objetivos más prácticos: dejar de pertenecer a una marginalidad que, hasta entonces, se había interpretado en términos de resistencia desde un punto de vista mayoritariamente sociopolítico y que ahora es, principalmente, industrial y cultural. Lo cierto es que, como podemos colegir de la letra de la canción que pone punto y final a la película, interpretada por Leño y de título Este Madrid ("bebemos, fumamos y nos colocamos. Tenemos plena libertad"), la situación había cambiado; en estos momentos, tal y como indica Giulia Quaggio en relación a los jóvenes del momento:

Su energía, orientada hacia el renacimiento cultural, se concentró en pequeños grupos sociales, salidas nocturnas y locales, música rock o pop. Los primeros pasos en la senda de la recuperación y apropiación de la nueva realidad conllevaron una relación diferente con la música de masas en tanto que medio e instrumento capaz de posibilitar originales signos de identificación colectiva (2014: 193).

${ }^{31}$ El periodista acababa recomendando: "Olvídese de los prejuicios, ignore su edad y anímese a asistir a un concierto de rock. Es uno de los pocos momentos auténticamente libres que podrá vivir" (70).

32 Esto no es del todo así pues éste queda parcialmente incluido en la película en las secuencias iniciales y en las finales.

${ }^{33}$ Este protagonismo queda patente al final del film: la película cierra con el letrero "Con las actuaciones de:" y la sucesión de los nombres, sobrepuestos a imágenes, de cada uno de los grupos participantes en el festival, a lo que le sigue el título "y 25.000 asistentes" sobrepuesto a una imagen del público que usa el zoom out para abrir el foco y mostrar a la multitud. 
Eso sí: en lo que sí coincidían estas propuestas (y algunas de las lecturas a las que dieron lugar) es en la identificación entre democracia y juventud en España, que tiene lugar en el ámbito de lo cultural ${ }^{34}$. Ciertas voces progresistas reclamaron el cambio en un país en el que una determinada juventud parecía haber encontrado los huecos suficientes para expresar unas inquietudes similares a las de los países democráticos y parecían entender, como indica Sánchez León en su estudio de los jóvenes durante la Transición, que:

por su cultura y su conciencia política, los jóvenes eran distintos. Lo que los convertía en potencialmente peligrosos, lo que disparaba los prejuicios contra ellos en un sentido que iba más allá del cálculo y la estrategia, era la reunión de sus personas, en las personas de muchos de ellos, de una doble singularidad: el estar abiertos a la exploración a la vez con la cultura y con la política (2004: 172).

Aun con diversas maneras y objetivos diferentes, los tres documentales analizados así certificaban esto último.

${ }^{34}$ Esta idea, presente en algunas de las narrativas recientes sobre la Transición, hunde entonces sus raíces en esta época. Por ejemplo, Quaggio: "Estos jóvenes urbanos, hijos de la modernización de la España tecnocrática de los sesenta, proyectaban su presencia en el espacio urbano metropolitano de la democracia" (2014: 193). Redactado ya el texto, hemos encontrado un artículo "Estigma y memoria de los jóvenes de la transición", escrito por el historiador Pablo Sánchez León, donde se indica lo siguiente: "no hay una verdadera historia alternativa de la transición esencialmente porque nadie ha sido capaz de identificar algún sujeto que encarnase en su trayectoria colectiva una salida diferente para los acontecimientos entre 1975 y 1982 (o 1989). Lo que anima a estas páginas es la pretensión de al menos esbozar con alguna evidencia la idea de que lo más parecido a ese sujeto fueron los jóvenes españoles de la época, especialmente aquellos nacidos y socializados en medios urbanos y pertenecientes a las clases medias" (2004: 165); el presente texto participa de esta intención. Agradezco a Violeta Ros que me hiciera llegar este artículo. 


\section{Bibliografía citada}

Aragüez Rubio, Carlos. "La nova cançó catalana: génesis, desarrollo y trascendencia de un fenómeno cultural en el segundo franquismo". Pasado y memoria. Revista de Historia contemporánea 5 (2006): 81-97.

Batista, Antoni. "A todos les va la marcha”. La Calle 17 (18-24/07/1978): 27-31.

Benet, Vicente J., "La imagen de Pasionaria en los años setenta: un caso de reciclaje del carisma en procesos de transición política". Iberic@l. Revue d'études ibériques et ibéro-americaines 4 (2013): 41-53.

Bueno, Juan B. "Nos va la marcha". Mundo Obrero (12/6/1979).

Cándido. "Teoría de Malasaña". ABC(17/2/1980): 121.

Clarke, John, Hall, Stuart, Jefferson, Tony y Roberts, Brian (2014). Rituales de resistencia. Subculturas juveniles en la Gran Bretaña de postguerra. Madrid: Traficantes de sueños.

Claret, Andreu y Luzán, Julia. "A los 15, de vuelta de todo". La Calle 33 (7-13/11/1978): 30-34.

Costa, José Manuel. "La violencia en los conciertos de «rock». Una plaga en la música de nuestro país". El País (10/10/1978): 60.

Cruz, José Ignacio. "Del autoritarismo a la coparticipación. La transición a la democracia y políticas de juventud en España". Historia de la educación. Revista interuniversitaria 22-23 (2003-2004): 195-212.

Gómez-Font, Álex (2011). Barcelona, del rock progresivo a la música layetana y Zeleste. Lleida: Milenio.

Gómez Vaquero, Laura (2012). Las voces del cambio. La palabra en el documental de la Transición en España. Madrid: Ayuntamiento de Madrid.

Granados, Chema (2009). La calle no calla!! Una historia del rock urbano en España. Barcelona: Quatentena ediciones.

Harguindey, Ángel S. "Guía inútil de los conciertos de rock". Cinema 2002 (1/10/1983): 69.

Haro Ibars, Eduardo y Covián, Marcelo. "Canet Rock: una puerta abierta". Triunfo 671 (9/8/1975): 26-27.

Jaraba, Gabriel. "Película de la película". Diario de Barcelona (16/6/1976): 21.

Lahosa, J. E. "Canet Rock". Avui (16/12/1976).

M. C., J. "Rocktiembre 78: 'rock', violencia y Teddy Bautista". El País (26/9/1978): 32.

Mainer, José-Carlos (2006). "La cultura de la Transición o la Transición como cultura". Molinero, Carme (ed.). La Transición, treinta años después. De la dictadura a la instauración de la democracia. Barcelona: eds. Península: 153-171. 
Mainer, José-Carlos y Santos Juliá (2000). El aprendizaje de la libertad (1973-1986). La cultura de la Transición. Madrid: Alianza.

Palacio, Manuel (2012). El cine y la transición política en España (1975-1982). Madrid: Biblioteca Nueva.

Quaggio, Giulia (2014). La cultura en transición. Reconciliación y política cultural en España, 1976-1986. Madrid: Alianza.

Rodríguez "Rodri”, José Manuel. "Conciertos de música pop-rock...". Amorós, Andrés y Díez Borque, José M.' (coords.). Historia de los espectáculos en España. Madrid: Editorial Castalia: 387-402.

Sánchez-Biosca, Vicente. "Las culturas del tardofranquismo". Ayer 68 (2007): 89-110.

Sánchez León, Pablo (2004). "Estigma y memoria de los jóvenes de la transición". Emilio Silva, Pancho Salvador, María Socorro Asunción, Esteban Recio y Javier Castán (coords.). La memoria de los olvidados: un debate sobre el silencio de la represión franquista. Valladolid: Ámbito ediciones: 163-182.

Stam, Robert (2001). Teorías del cine: una introducción. Barcelona: Paidós.

Trenzado Romero, Manuel (1999). Cultura de masas y cambio político: el cine español de la transición. Madrid: Centro de Investigaciones Sociológicas.

Turtós, Jordi (1995). "Pogressius i laietans". Duran, Sílvia y Guerrero, Manuel. Alter Músiques Natives. Barcelona: Generalitat de Catalunya: 75-81.

Vázquez Montalbán, Manuel (1975). "Canet. Delirio democrático con música y letra”. Triunfo (26/07/1975): 19.

VV. AA. (1986). El cine y la transición política. Valencia: Filmoteca de la Generalitat Valenciana.

Ysàs, Pere (2006). "La crisis de la dictadura franquista". Molinero, Carme (ed.). La Transición, treinta años después. De la dictadura a la instauración de la democracia. Barcelona: eds. Península: 27-58. 